\title{
Condities op combineerbaarheid. Het geval van de bepaling van de gesteldheid en de PP
}

\begin{abstract}
Secondary predicates are known to be hybrids. The secondary predicate warm in Jan eet die Hollandse kroketjes warm is depending both on the VP predicate eet and on the NP die Hollandse kroketjes. It has also been indicated that a secondary predicate can be governed by some types of PP's. Compare the direct object van die Hollandse kroketjes in Jan eet [van die Hollandse kroketjes] PPwarm with the prepositional object van die Hollandse kroketjes in: *Jan eet [van die Hollandse kroketjes $]_{P P}$ warm. In the first sentence, 'Jan' eats an unlimited amount of 'Dutch croquettes', while what 'Jan' in the second sentence does is eating pieces of unlimited amount of 'Dutch croquettes'. The difference between the acceptability of the two constructions tends to be analysed in two ways: 1. the first sentence is acceptable because the direct object is in fact not a PP but a NP, which is preceded by a complex determinator van die or 2 . the construction is acceptable because it contains a PP which refers to entities. The aim of this paper is to further support the second opinion.
\end{abstract}

Keywords: Dutch, syntax, secondary predicates, NP, PP, syntactic category, syntactic function

\section{Probleemstelling}

We weten dat de bepaling van gesteldheid (BVG) een hybride is. Zie de AP warm in (1) die de functie 'tijdens de handeling' vervult (Haeseryn e.a. 1997, Van Belle e.a. 2011). ${ }^{1}$

(1) Jan eet [die Hollandse kroketjes $]_{\mathrm{NP}}$ altijd [warm $]_{\mathrm{AP}}$

${ }^{1}$ De gepresenteerde acceptabiliteitsoordelen zijn tot stand gekomen op grond van een schriftelijk informantenonderzoek. In deze bijdrage betekent acceptabel: $\geq 12$ van de 16 informanten vinden de uiting acceptabel of min of meer acceptabel, terwijl onacceptabel staat voor: $\leq 4$ van de 16 informanten vinden de uiting acceptabel of min of meer acceptabel, aangegeven door * voor het voorbeeldnummer. Het label twijfelachtig wordt gereserveerd voor de resterende uitingen, aangegeven door? Het interval tussen 12/16 en 4/16 is significant op het 95\%-niveau (Van Wijk 2008). 
Deze constituent wordt zowel betrokken op eet ('warm eten'), als op de NP die Hollandse kroketjes ('warme Hollandse kroketjes'). Met andere woorden: tijdens de handeling van het eten zijn 'de Hollandse kroketjes' warm. Verder is het bekend dat de BVG combineerbaar is met sommige types PP's, terwijl andere types niet combineerbaar zijn (De Hoop e.a. 1990). Vergelijk het direct object (DOB) van die Hollandse kroketjes in (2) met het prepositioneel object (POB) van die Hollandse kroketjes in (3)-(4).

(2) Jan eet [van die Hollandse kroketjes $]_{\mathrm{PP}}$ altijd [warm $]_{\mathrm{AP}}$

DOB

(3) Jan eet $[\text { van die Hollandse kroketjes }]_{P P}$

$\mathrm{POB}$

(4)* Jan eet[van die Hollandse kroketjes $]_{\mathrm{PP}}$ altijd $[\text { warm }]_{\mathrm{AP}}$

POB

In (2) eet 'Jan' een onbepaald aantal 'Hollandse kroketjes' waarvan de gesteldheid tijdens de handeling als 'warm' wordt gekwalificeerd (eten), terwijl 'Jan' in (3) 'stukjes' eet van een onbepaald aantal 'Hollandse kroketjes' (eten van). Zoals (4) laat zien, kan de gesteldheid van de betreffende entiteiten nu niet worden uitgedrukt. In de vakliteratuur wordt het contrast tussen (2) en (4) grosso modo op twee manieren geanalyseerd. Volgens Haegeman (1987), De Hoop e.a. (1990), Haeseryn e.a. (1997) en Broekhuis \& Den Dikken (2012) is (2) acceptabel omdat van die Hollandse kroketjes in tegenstelling tot van die Hollandse kroketjes in (4) in staat is naar entiteiten te verwijzen. Volgens de auteurs betekent dit dat de ogenschijnlijke PP van (2) in feite een NP is. ${ }^{2}$ Van die moet derhalve als een complexe determinator worden beschouwd (De Hoop e.a. 1990). Zie (5).

(5) Jan eet [van die Hollandse kroketjes $]_{\mathrm{NP}}$ altijd warm complexe determinator

Conclusie: er wordt hier een verband gelegd tussen het verwijzingsgedrag van de syntactische categorieën NP en PP en de combineerbaarheid met de BVG. Zie schema 1.

\begin{tabular}{|c|c|}
\hline verwijzing naar entiteiten & combineerbaarheid BVG \\
\hline NP verwijst & + \\
\hline PP verwijst niet & - \\
\hline
\end{tabular}

Schema 1. Verwijzingsgedrag syntactische categorie en combineerbaarheid BVG

${ }^{2}$ Of eventueel een DP. 
De andere analyse is afkomstig van Van der Lubbe (1982), Paardekooper (1986) en Sturm (1989). Zij zijn van mening dat van die Hollandse kroketjes in (2) combineerbaar is met de BVG warm, omdat we hier te maken hebben met een PP die in staat is naar entiteiten te verwijzen. Van die Hollandse kroketjes in (4) daarentegen is onacceptabel, omdat deze PP niet naar entiteiten verwijst. ${ }^{3} \mathrm{De}$ verklaring is dat de $\mathrm{PP}$ in (2) de syntactische functie DOB vervult, terwijl de PP in (4) die van POB bekleedt. Hier wordt dus een verband gelegd tussen het verwijzingsgedrag van de syntactische functies DOB en POB en de combineerbaarheid met de BVG. Zie schema 2.

\begin{tabular}{|c|c|}
\hline verwijzing naar entiteiten & combineerbaarheid BVG \\
\hline DOB verwijst & + \\
\hline POB verwijst niet & - \\
\hline
\end{tabular}

Schema 2. Verwijzingsgedrag syntactische functie en combineerbaarheid BVG (versie 1)

Het doel van deze bijdrage is deze tweede visie zowel te ondersteunen als verder uit te werken. Ziehier onze opzet. We gaan ten eerste in op het PP-DOB en proberen aan te tonen dat de NP-analyse van Haegeman (1987), De Hoop e.a. (1990), Haeseryn e.a. (1997) en Broekhuis \& Den Dikken (2012) moeilijk houdbaar is. Anders geformuleerd: de combineerbaarheid van de BVG met PP's als in (2) hangt ons inziens niet samen met de voorgestelde NP-status van de laatste. Ten tweede laten we aan de hand van zogenaamde elliptische PP-DOB's zoals met Belgische mayonaise zien dat de analyse van Van der Lubbe (1982), Paardekooper (1986) en Sturm (1989) verfijnd dient te worden. De observatie dat dergelijke PP's niet altijd combineerbaar zijn met de BVG is te verklaren met een beroep op de parameter 'affectie' (affectedness) (Hopper \& Thompson 1980, Gropen e.a. 1991). We eindigen met enkele voorlopige conclusies.

\section{Het niet elliptische PP-DOB}

De vraag rijst hoe Haegeman (1987), De Hoop e.a. (1990), Haeseryn e.a. (1997) en Broekhuis en Den Dikken (2012) ertoe komen om van die Hollandse kroketjes in (2) als een NP te beschouwen. De laatsten merken in dit verband op: "(...) that the projection of $\mathrm{N}_{2}$ is a nominal disguised as a van die $N$ phrase with a spurious preposition van" (2012: 631). Zoals reeds opgemerkt, stellen De Hoop e.a. (1990)

${ }^{3}$ De van die-PP in (2) is uitzonderlijk in die zin dat PP's doorgaans juist niet naar entiteiten verwijzen, maar bijvoorbeeld naar 'tijd' (om 15.00 uur), 'plaats' (op het station), 'richting' (naar Antwerpen), enzovoorts. Voor een overzicht, zie Haeseryn e.a. (1997). 
voor deze "spurious preposition" in de determinator op te nemen. We moeten toegeven dat er een solide argument bestaat. De syntactische functies van de PP en de NP in (6) en (7) zijn immers identiek, namelijk DOB. Dit betekent dat deze functie in (6) niet gemarkeerd wordt door de prepositie van.

(6) Jan eet [van die Hollandse kroketjes $]_{P P}$ altijd warm DOB

(7) Jan eet [die Hollandse kroketjes $]_{\mathrm{NP}}$ altijd warm DOB

Het is echter aantoonbaar dat dit voorzetsel wel de semantische functie van de PP markeert (Pekelder 2000). Er bestaat namelijk een opmerkelijk semantisch verschil tussen (6) en (7). In de eerste uiting wordt de verzameling die Hollandse kroketjes via van in verband gebracht met een deelverzameling in het interpretatiedomein. ${ }^{4}$ Anders geformuleerd: van markeert partitiviteit. Zie (8).
(8) Jan eet $\varnothing$
van die deelverzameling $\subset$
Hollandse kroketjes verzameling

We wijzen erop dat hier geen sprake kan zijn van een elliptisch PP-DOB en dus een NP, omdat deze deelverzameling niet lexicaliseerbaar is. Zie (9). ${ }^{5}$
(9) * Jan eet
Hollandse kroketjes van deelverzameling
$\subset$
die Hollandse kroketjes verzameling

Aangezien de deelverzameling verplicht verondersteld wordt, is van die Hollandse kroketjes slechts presuppositioneel interpreteerbaar: er ontstaat een zogenaamd 'je-weet-wel-effect': 'je weet wel wat ik bedoel als ik het over Hollandse kroketjes heb'. In (7) daarentegen waar de prepositie ontbreekt en dus geen sprake is van partitiviteit, kan die Hollandse kroketjes zowel presuppositioneel, anaforisch als deiktisch geïnterpreteerd worden. Deze drie interpretatiemogelijkheden

${ }^{4}$ Onder interpretatiedomein verstaan we het geheel aan niet taalkundige parameters dat invloed uitoefent op de interpretatie van een taaluiting. In het onderhavige geval gaat het om de parameter gedeelde zender-ontvanger-kennis (De Jong e.a. 1988).

${ }^{5}$ Een mogelijke bron van verwarring vormen uitingen als Jan koopt exemplaren van die spannende boeken waar de deelverzameling wel gelexicaliseerd lijkt te zijn. Er is hier echter geen sprake van een partitief. In partitieven bevat de verzameling immers verplicht meer dan één lid (Pekelder 1993). Vergelijk Jan eet een handvol van de kersen en * Jan eet een handvol van de kers met Jan koopt exemplaren van dat spannende boek. 
worden, zoals bekend, afgedwongen door het aanwijzend voornaamwoord die (Pekelder 2002). ${ }^{6}$ Vergelijk respectievelijk (10)-(12).

(10) Jan eet die Hollandse kroketjes

[presuppositioneel: 'je weet wel wat ik bedoel als ik het over Hollandse kroketjes heb']

(11) Jan eet die Hollandse kroketjes [anaforisch: 'de Hollandse kroketjes waar ik net over sprak']

(12) Jan eet die Hollandse kroketjes [deiktisch: 'de Hollandse kroketjes die daar liggen']

Kortom, de stelling dat het DOB van die Hollandse kroketjes in (2) in feite een NP is, is moeilijk houdbaar. Het voorzetsel van is gezien zijn specifieke semantische functie wel degelijk een discreet onderdeel van de constituent: door een niet genoemde deelverzameling te includeren in de genoemde verzameling filtert het de anaforische en deiktische interpretatie uit. Slechts de presuppositionele lezing blijft over. Hiermee wordt de onbepaalde lezing van de van die-PP verklaard. ${ }^{7}$ Deze observaties blijven echter onverklaard onder een NP-lezing van van die Hollandse kroketjes. ${ }^{8}$ Hiermee vervalt het door Haegeman (1987), De Hoop e.a. (1990), Haeseryn e.a. (1997) en Broekhuis \& Den Dikken (2012) gelegde verband tussen het verwijzingsgedrag van de syntactische categorieën NP en PP en de combineerbaarheid met de BVG. Zie nogmaals schema 1. PP's als in (2) blijken wel degelijk naar entiteiten te kunnen verwijzen mits hun syntactische functie niet gemarkeerd wordt door het voorzetsel. Zoals Van der Lubbe (1982), Paardekooper (1986) en Sturm (1989) reeds suggereerden, hangt het verschil in acceptabiliteit tussen (2) en (4) derhalve samen met het verschillende verwijzingsgedrag van de syntactische functies DOB en POB. ${ }^{9}$ Een functie als DOB staat ver-

${ }^{6}$ Terzijde zij opgemerkt dat zogenaamde partitieve NP's, die worden ingeleid door een kwantitatieve NP, als een handvol van die Hollandse kroketjes zowel presuppositioneel, anaforisch als deiktisch geïnterpreteerd kunnen worden, dankzij de kwantificering van de niet genoemde deelverzameling (Pekelder 2002).

${ }^{7}$ Het onbepaalde karakter van deze PP blijkt uit er liggen van die Hollandse kroketjes op mijn bord.

${ }^{8}$ We wijzen erop dat ook uitingen als hij liep gehuld in van die rare kleren geen valide argument vormen voor een eventuele NP-lezing van de van-die-constituent, omdat $\mathrm{PP}=\mathrm{P}+\mathrm{XP}$ en niet slechts P + NP (Sturm 1986, Haeseryn 1997, Pekelder 2002). Zie ook hij liep tot aan de brug, dat is voor bij de koffie, dat dateert van voor mijn benoeming, met van dat soort leerlingen heb ik weinig moeite (telkens $\mathrm{P}+\mathrm{PP})$, dat is voor eens in de week $(\mathrm{P}+\mathrm{Adv})$ en dat dateert van toen ik klein was $(\mathrm{P}+\mathrm{CP})$.

${ }^{9}$ Het debat rond de vraag of een bepaald verwijzingsgedrag eigen is aan een specifieke syntactische functie of aan een specifieke syntactische categorie is in wezen een discussie over het onderscheid tussen functie en categorie. Zoals onder andere Hagège (1982) en Feuillet (1986) laten zien, gaan taalkundigen, met name binnen de generatieve syntaxis, niet altijd even zorgvuldig met dit onderscheid om. Omdat we hier niet dieper op deze zaak kunnen ingaan, volstaan we met de opmer- 
wijzing naar entiteiten toe, in tegenstelling tot een functie als POB. Zie nogmaals schema 2.

We vinden verdere ondersteuning voor deze analyse als we kijken naar de twee andere types BVG, 'volgens' en 'ten gevolge van de handeling'. Het blijkt dat het niet elliptische PP-DOB combineerbaar is met beide. Zie respectievelijk (13)-(14) en (15)-(16). ${ }^{10}$

(13) Jan vindt $\quad$ [van die Hollandse kroketjes $]_{\mathrm{PP}}$

DOB

(14) Jan vindt [van die Hollandse kroketjes]pp lekkerder

DOB

(15) Jan maakt [van die Hollandse kroketjes] $]_{P P}$

DOB

(16) Jan maakt [van die Hollandse kroketjes] $]_{\mathrm{PP}}$ warm DOB

Conclusie: in tegenstelling tot de analyse van Haegeman (1987), De Hoop e.a. (1990), Haeseryn e.a. (1997) en Broekhuis \& Den Dikken (2012) maar in overeenstemming met die van Van der Lubbe (1982), Paardekooper (1986) en Sturm (1989) blijkt het beroep op de syntactische categorie NP geen noodzakelijke voorwaarde te vormen voor de verwijzing naar entiteiten. Desondanks is er ook met de laatste analyse een probleem. Daaraan is de volgende paragraaf gewijd.

\section{Het elliptische PP-DOB}

Het in schema 2 uitgedrukte verband tussen het verschillende verwijzingsgedrag van de syntactische functies $\mathrm{DOB}$ en $\mathrm{POB}$ en de eventuele combineerbaarheid met de BVG dient genuanceerd te worden. Het is namelijk aantoonbaar dat een beroep op de syntactische functie DOB niet systematisch een voldoende voorwaarde vormt voor de combineerbaarheid met de BVG. Het blijkt dat zogenaamde elliptische PP-DOB's als met Belgische mayonaise hoewel combineerbaar met de BVG 'volgens de handeling', niet combineerbaar zijn met BVG's 'tijdens' en 'ten gevolge van de handeling'. ${ }^{11}$ Zie respectievelijk (17)-(19).

king dat voormelde NP-lezing van de van-die-constituent erop lijkt te wijzen dat Haegeman (1987), De Hoop e.a. (1990), Haeseryn e.a. (1997) en Broekhuis \& Den Dikken (2012), in het onderhavige geval, uitgaan van een één-op-één-relatie tussen functie en categorie: daar de van-die-constituent naar entiteiten verwijst en dus een potentieel DOB is, kan het niet anders dan een NP zijn.

${ }^{10}$ We gaan hier niet in op de semantische verschillen van vinden en maken met en zonder BVG.

${ }^{11}$ Het elliptische karakter van het PP-DOB blijkt uit het feit dat we in (17) het lege nominale hoofd kunnen vervangen door friet: Jan vindt [friet [met Belgische mayonaise] $\left.{ }_{P P}\right]_{N P}$ lekkerder. We komen hierop terug in paragraaf 4. 
(17) Jan vindt

$\left[\varnothing[\text { met Belgische mayonaise }]_{\mathrm{PP}}\right]_{\mathrm{NP}}$ lekkerder DOB

(18) * Jan eet

$\left[\varnothing[\text { met Belgische mayonaise }]_{P P}\right]_{N P}$ altijd warm DOB

(19) * Jan maakt

$\left[\varnothing[\text { met Belgische mayonaise }]_{P P}\right]_{N P}$ warm DOB

Schema 2 moet bijgevolg verfijnd worden. Blijkbaar is het verband tussen het verwijzingsgedrag van de syntactische functies DOB en POB en de combineerbaarheid met de BVG partieel. Zie schema 3.

\begin{tabular}{|c|c|c|}
\hline & BVG & \\
\cline { 2 - 3 } & volgens de handeling & tijdens/t.g.v. de handeling \\
\hline -elliptisch PP-DOB verwijst & + combineerbaar & + combineerbaar \\
\hline POB verwijst niet & -combineerbaar & -combineerbaar \\
\hline +elliptisch PP-DOB verwijst & + combineerbaar & -combineerbaar \\
\hline
\end{tabular}

Schema 3. Verwijzingsgedrag syntactische functie en combineerbaarheid BVG (versie 2)

In de volgende paragraaf proberen we hier een verklaring voor te geven.

\section{Affectie}

Ter verklaring van het verschillende gedrag van het niet elliptische en het elliptische PP-DOB met betrekking tot de BVG's 'tijdens' en 'ten gevolge van de handeling' doen we een beroep op het concept 'affectie'. Hopper \& Thompson formuleren het als volgt: "The degree to which an action is transferred to a patient is a function of how completely that patient is AFFECTED; it is done more effectively in, say, I drank up the milk than in I drank some of the milk" (1980: 252-253). In beide voorbeelden is sprake van verplaatsing van 'de melk'. In de eerste uiting verandert de vloeistof in haar geheel van plaats, terwijl die in het tweede voorbeeld slechts ten dele van plaats verandert. Affectie is overigens niet beperkt tot plaatsveranderingen, maar kan, onder andere, ook betrekking hebben op toestandsveranderingen (Gropen e.a. 1991). Een uiting als I warmed up the milk geeft aan dat 'de melk' in een andere (bio)chemische toestand verkeert dan voor het opwarmen. Kijken we nu naar (17)-(19).

Als we het elliptische PP-DOB van (17) vergelijken met dat van (18)-(19), constateren we dat in de eerste uiting de aangewezen entiteiten niet geaffecteerd worden door het verbale predicaat. Het gaat immers om de opinie van 'Jan' uitgedrukt door vindt. Met andere woorden: het feit dat 'Jan' de 'Hollandse kroketjes' 
lekkerder vindt, verandert noch iets aan hun plaats, noch aan hun toestand. In de andere twee uitingen daarentegen zijn of worden deze entiteiten wel geaffecteerd dankzij eet en maakt. De 'Hollandse kroketjes' in (18) zijn 'warm', terwijl die in (19) in een nabije toekomst 'warm' zullen zijn. Er is dus duidelijk sprake van een (toekomstige) toestandsverandering. Dit wijst erop dat er een verband bestaat tussen type BVG en affectie. Zie schema 4.

\begin{tabular}{|c|c|}
\hline BVG & affectie \\
\hline volgens de handeling & - \\
\hline tijdens de handeling & + \\
\hline t.g.v. de handeling & + \\
\hline
\end{tabular}

Schema 4. Type BVG en affectie

De vraag rijst ten slotte waarom het elliptische PP-DOB in (18)-(19) niet geaffecteerd kan worden door het verbale predicaat. Het antwoord moet gezocht worden in het contrast tussen het niet elliptische PP-DOB en het PP-POB. De BVG kan slechts de gesteldheid uitdrukken van entiteiten indien er effectief naar deze verwezen wordt. ${ }^{12}$ Hoewel het PP-DOB, zoals we zagen, verbonden is met een niet lexicaliseerbare deelverzameling entiteiten die slechts terugvindbaar is binnen het interpretatiedomein, verwijst deze constituent effectief naar deze entiteiten dankzij de in de PP vervatte NP. Zie opnieuw (8), hier herhaald als (20).
(20) Jan eet $\varnothing$
[van
[die Hollandse kroketjes $\left.]_{\mathrm{NP}}\right]_{\mathrm{PP}}$
deelverzameling
$\subset \quad$ verzameling

Zoals het elliptische PP-DOB in (17) laat zien, mag het eventueel om een default-verwijzing gaan onder de voorwaarde dat het verbale predicaat de entiteiten niet affecteert. De vraag rijst uiteraard hoe deze default-verwijzing werkt. Het blijkt dat in het geval van een leeg nominaal hoofd de verwijzing wordt opgepakt door de BVG, hier lekkerder, in die zin dat die het bestaan veronderstelt van een of meer entiteiten $\mathrm{x}$ : lekkerder $\rightarrow \mathrm{x} .{ }^{13}$ Conclusie: de condities op de combineerbaarheid van BVG en PP gaan terug op twee parameters: het verwijzingsgedrag van de onderhavige syntactische functies en affectie. Zie schema 5.

12 'Effectieve verwijzing' staat hier tegenover 'default-verwijzing'. Zie verderop.

13 Dit verklaart tevens dat geen van de constructies in (17)-(19) acceptabel is zonder BVG: * Jan vindt met Belgische mayonaise, * Jan eet met Belgische mayonaise en * Jan maakt met Belgische mayonaise. Zonder een lexicaal nominaal hoofd is verwijzing onmogelijk. 


\begin{tabular}{|c|c|c|}
\hline verwijzing naar entiteiten & $\begin{array}{c}\text {-affectie } \\
\text { (volgens de handeling) }\end{array}$ & $\begin{array}{c}+ \text { affectie } \\
\text { (tijdens/t.g.v. de handeling) }\end{array}$ \\
\hline effectief (-elliptisch PP-DOB) & + combineerbaar & + combineerbaar \\
\hline geen (POB) & -combineerbaar & -combineerbaar \\
\hline default (+elliptisch PP-DOB) & + combineerbaar & -combineerbaar \\
\hline
\end{tabular}

Schema 5. Condities op combineerbaarheid BVG en PP

Onze hypothese wordt verder ondersteund door (21) waar we de PP-POB hebben vervangen door een NP met de functie DOB. Door invoeging van stukjes ontstaat er effectieve verwijzing en krijgen we dus acceptabele uitingen.

(21) Jan eet [stukjes van die Hollandse kroketjes $]_{\mathrm{NP}}$ altijd warm

Hetzelfde gaat op voor het elliptische PP-DOB. De invoeging van friet resulteert in acceptabele uitingen. Zie (22)-(23).

(22) Jan eet [friet met Belgische mayonaise $]_{\mathrm{NP}}$ altijd warm

(23) Jan maakt [friet met Belgische mayonaise $]_{\mathrm{NP}}$ warm

In tegenstelling tot het elliptische PP-DOB en het PP-POB, maar zoals het niet elliptische PP-DOB verwijzen NP's effectief naar entiteiten. In dat geval speelt de parameter 'affectie' dan ook geen rol meer.

\section{Conclusies}

PP's zijn onder twee voorwaarden combineerbaar met de BVG. In de eerste plaats is het niet elliptische PP-DOB combineerbaar met de drie types BVG, omdat deze constituent in staat is effectief naar entiteiten te verwijzen via de NP die die bevat. Daar het PP-POB niet naar entiteiten verwijst, is deze constituent niet combineerbaar. De tweede voorwaarde hangt samen met het concept 'affectie'. Het elliptische PP-DOB is combineerbaar onder de conditie dat de BVG de entiteiten waarvan die het bestaan veronderstelt (default-verwijzing) niet affecteert. Hieruit volgt dat de BVG 'volgens de handeling' combineerbaar is en de BVG's 'tijdens' en 'ten gevolge van de handeling' niet combineerbaar. 


\section{Bibliografie}

Belle, William van e.a. (2011): Nederlandse grammatica voor Franstaligen. KUL, 11.12.2011, laatst geraadpleegd op 15.01.2017 (http://www.arts.kuleuven.be/ling/project/ngf).

Broekhuis, Hans \& Dikken, Marcel den (2012): Syntax of Dutch. Nouns and Noun Phrases, Vol. 2. Amsterdam: Amsterdam University Press.

Feuillet, Jack (1986): “Catégories et fonctions”. In: L'Information Grammaticale 31: 3-7.

Gropen, Jess e.a. (1991): "Affectedness and direct objects: The role of lexical semantics in the acquisition of verb argument structure". In: Cognition 41: 153-195.

Haegeman, Liliane (1987): "Van constructions in Dutch". In: Beukema, Frits \& Coopmans, Peter (ed.): Linguistics in the Netherlands 1987. Dordrecht: Foris, 61-70.

Haeseryn, Walter e.a. (1997): Algemene Nederlandse Spraakkunst. Groningen: Martinus Nijhoff / Deurne: Wolters Plantyn.

Hagège, Claude (1982): La structure des langues. Paris: PUF.

Hoop, Helen de e.a. (1990): "Syntaxis en semantiek van de van die-constructie". In: Gramma 14: 81-106.

Hopper, Paul J. \& Thompson, Sandra A. (1980): “Transitivity in grammar and discourse”. In: Language 56, 2: 251-299.

Jong, Franciska de e.a. (1988): Betekenis en taalstructuur. Inleiding in de formele semantiek. Dordrecht: Foris Publications.

Paardekooper, Piet C. (1986): Beknopte ABN-syntaksis. Eindhoven, uitgave in eigen beheer ( $7^{\mathrm{e}} \mathrm{druk}$ ), laatst geraadpleegd op 15.01.2017 (http://www.dbnl.org/tekst/paar001bekn02_01/).

Pekelder, Jan (1993): Conventies en functies. Aspecten van binominale woordgroepen in het hedendaagse Nederlands. Bibliothèque des Cahiers de l'Institut de Linguistique de Louvain, nr. 71. Louvain-la-Neuve: Peeters.

Pekelder, Jan (2000): "Van die-verkenningen. Het contrast tussen de van-die-N- en de de-ces-Nconstructie". In: Leuvense bijdragen. Leuven contributions in linguistics and philology 89, 1-2: 203-214.

Pekelder, Jan (2002): Décodage et interprétation. Ordres linguistique, iconique et pragmatique en néerlandais contemporain. Bibliothèque des Cahiers de l'Institut de Linguistique de Louvain, nr. 110. Louvain-la-Neuve: Peeters.

Sturm, Arie (1989): "Vorm en functie van woordgroepen: de constructie met paradigmaloos van". In: De Nieuwe Taalgids 82: 529-553.

Van der Lubbe, Hendrik F.A. (1982): “Over echte en schijnbare partitieve woordgroepen”. In: Spektator 11: 367-378.

Van Wijk, Carel (2008): Toetsende statistiek. Basistechnieken. Een praktijkgerichte inleiding voor onderzoekers van taal, gedrag en communicatie. Bussum: Coutinho.

Jan Pekelder $\left({ }^{*} 1956\right)$ is syntacticus. Hij studeerde Nederlands, Frans en Algemene Taalwetenschap in Leiden, Straatsburg en Parijs. In 1992 promoveerde hij aan de Université Catholique de Louvain op de interne structuur van de Nederlandse NP. In 1999 habiliteerde hij aan de Université Paris-Sorbonne, onder andere op constituentenvolgorde in het hedendaags Nederlands. Hij is momenteel gewoon hoogleraar in de synchrone taalkunde aan de Sorbonne en buitengewoon hoogleraar in de Nederlandse taalkunde aan de Univerzita Karlova v Praze. Hij publiceerde diverse boeken en artikelen op het gebied van de syntaxis en de NVT-didactiek.

e-mail: jan.pekelder@gmail.com 